\title{
Desde la invisibilidad y la precariedad: nuevos horizontes para la colectivización de las trabajadoras de hogar
}

\author{
Angie Larenas Álvarez \\ <angie_larenas@yahoo.es> \\ Oihane Garcia \\ Departamento de Sociología II, Universidad del País Vasco (UPV-EHU) \\ Josefina Roco
}

Artikulu honen helburu nagusia da etxeko lanaren irudi orokorra lausotzea etxeko langileen balorazio eta esanguretatik abiatuz. Era berean, euren kolektibotasunerako positiboak diren aukeren espazioak bilatu. Zentzu horretan, sektorearen egungo baldintzen testuingurua luzatu, arautegi berriaren eragina hausnartu eta etxeko lana esanguraz betetzeko espazioak bilatuko ditugu. 2012 eta 2013 urte bitartean burututako Necesidades y oportunidades de las trabajadoras de hogar de Basauri. Una experiencia de intervención colectiva ikerketa kualitatiboan du jatorria artikulu honek. Modu kolaboratiboan egindako askoren lana da hau, etxeko lanean emakume-ikustezin-prekario argazkiarekin apurtu nahi du, eta etxeko lanaren etengabeko produkzioa-erreprodukzioa emateko elementuen konplexutasuna agerian uzten du.

\section{GAKO-HITZAK:}

Etxeko lana, lan erreproduktiboa, emakumeak, generoa, arautegia, esangura espazioak.
El objetivo principal del artículo es desdibujar la ilustración global del trabajo de hogar a través de las valoraciones y significaciones de las propias trabajadoras, y buscar espacios de oportunidad para trazar rumbos que incidan positivamente en su colectivización. En este sentido, contextualizaremos las condiciones actuales del sector, indagaremos en el impacto de la nueva normativa que lo regula y buscaremos espacios de resignificación del trabajo de hogar. El artículo tiene su origen en la investigación Necesidades y oportunidades de las trabajadoras de hogar de Basauri. Una experiencia de intervención colectiva, un estudio cualitativo realizado entre 2012 y 2013 . Su objetivo principal fue trazar líneas de actuación conjunta y colaborativa para romper con la foto fija mujeres-invisibilizadasprecarizadas en el trabajo doméstico, y poner en evidencia la complejidad de elementos que posibilitan la constante producción y reproducción del trabajo de hogar en las condiciones en que lo conocemos.

\section{Palabras Clave:}

Trabajo doméstico, trabajo reproductivo, mujeres, género, normativa, espacios de significación. 


\section{Introducción}

El trabajo de hogar se asocia con determinadas características reproductivas asignadas a las mujeres en el marco del sistema patriarcal. Se trata de un trabajo naturalizado, desempeñado tradicionalmente de manera gratuita. Al salir del estrecho marco familiar y convertirse en trabajo remunerado, se produce un continuum entre lo pautado por la tradición y la manera en que se percibe, se vive y se reproduce ese trabajo de hogar.

En la actualidad, los avances en materia de igualdad entre mujeres y hombres se han mostrado incapaces de superar la barrera existente entre trabajo productivo y trabajo reproductivo. La importancia de este último es poco debatida y escasamente considerada socialmente, por lo que no es de extrañar que persista una visión esencializada del trabajo de hogar y que se reproduzca como un empleo feminizado, invisible y precario. El pensamiento feminista ha puesto sobre la mesa la realidad de este tipo de trabajo, pero todavía falta mucho por hacer. De ahí que nuestro objetivo se centre en la necesidad de des-dibujar la ilustración global del trabajo de hogar a través de las valoraciones y significaciones de las propias trabajadoras, y buscar, de este modo, espacios de oportunidad para trazar nuevos rumbos que incidan positivamente en su colectivización. Para ello, proponemos la utilización de un enfoque de género, que tiene como centro la comprensión y explicación de la multiplicidad de factores que se interrelacionan para reproducir la desigualdad entre hombres y mujeres.

El presente artículo tiene su origen en la investigación Necesidades y oportunidades de las trabajadoras de hogar de Basauri. Una experiencia de intervención colectiva (Roco et al., 2013) realizado junto al Área de Igualdad del Ayuntamiento de Basauri (Bizkaia) entre 2012 y 2013. El fin último de esta investigación era trazar líneas de actuación conjunta y colaborativa para romper con la foto fija mujeresinvisibilizadas-precarizadas en el trabajo doméstico, y poner en evidencia la complejidad de elementos que posibilitan la constante producción y reproducción del trabajo de hogar en las condiciones en que lo conocemos.

En la investigación se utilizó una metodología participativa, donde la generación y transferencia del conocimiento fue compartida. En el estudio participaron dieciocho trabajadoras de hogar, con las que se realizaron doce entrevistas en profundidad y un grupo de discusión. Las trabajadoras seleccionadas procedían de distintas zonas del Estado español y de América Latina; algunas de ellas se encontraban en situación administrativa irregular. Se trataba de trabajadoras en régimen externo (tanto con jornadas laborales completas como por horas) o interno, que desempeñaban labores domésticas o de cuidados. Todas contaban con una antigüedad mínima de dos años en el sector.

El artículo consta de cuatro apartados principales. En el primero, contextualizaremos la informalidad, invisibilidad e infravaloración del trabajo de hogar. Para ello, nos acercaremos a algunas definiciones relevantes para comprender el tema en cuestión, y también nos detendremos brevemente en los retos actuales de la localidad de Basauri en materia de trabajo de hogar. El segundo apartado corresponde a la descripción de la nueva normativa que regula el sector. Indagaremos en el impacto de las regulaciones en las trabajadoras, y en los déficits y desafíos para el trabajo de hogar en el contexto actual de crisis. En el tercer apartado, analizaremos los nuevos espacios de significación que las propias trabajadoras han construido a través de su discurso. En este sentido, destacamos tres elementos: la valoración de aportes y limitaciones del trabajo de hogar, la relevancia de la red de relaciones de las trabajadoras y su participación social. Finalmente, indagaremos en los nuevos rumbos del trabajo de hogar. Para ello, también hemos seleccionado tres puntos centrales: el tránsito de la alta precarización a la mejora mínima de las condiciones de trabajo, de la invisibilidad a la revalorización del trabajo de hogar, y de la individualidad a la colectivización como ruta hacia la culminación de los tránsitos anteriores.

\section{Contextualización de la informalidad, invisibilidad e infravaloración del trabajo de hogar}

\subsection{Algunas definiciones de partida}

La Organización Internacional del Trabajo (2011) define el trabajo doméstico como aquel "realizado para, o dentro de, un hogar o varios hogares". Este trabajo puede incluir tareas como limpiar la casa, cocinar, lavar y planchar la ropa, cuidar de los niños y niñas, las personas enfermas o ancianas de una familia; la jardinería, la vigilancia de la casa, el desempeño como chófer familiar e incluso el cuidado de animales domésticos.

En este sentido, se considera como trabajadora ${ }^{1}$ de hogar a toda persona que realiza un trabajo doméstico en el marco de una relación laboral a tiempo completo o a tiempo parcial. Se trata de personas empleadas por uno o por varios empleadores, que residen en la casa donde trabajan (régimen interno) o en su propia residencia (régimen externo). Por su parte, se considera como empleadora a la persona con la que se establece el vínculo contractual y es miembro de la familia para la que se realiza el trabajo, así como a la agencia o empresa intermediaria que emplea a trabajadoras y las ofrece a los hogares.

En el ámbito del Estado español, el Real Decreto $1620 / 2011$, de 14 de noviembre, define la relación especial del servicio del hogar familiar como aquella

${ }^{1}$ Independientemente de que una persona trabajadora de hogar puede ser mujer u hombre, en el presente trabajo utilizamos el término 'trabajadora de hogar', porque más del $90 \%$ de las personas empleadas en el sector son mujeres, así como la totalidad de la muestra seleccionada para el estudio. 
"que conciertan el titular del mismo como empleador y la trabajadora que, dependientemente y por cuenta de aquél, presta servicios retribuidos en el ámbito del hogar familiar".

Es importante mencionar que, en el marco de dicha relación especial, ninguno de los tres elementos que intervienen son los clásicos de las relaciones laborales. En primer lugar, el hogar no es el típico ámbito laboral, lo que refiere a las condiciones particulares en las que se efectúa el trabajo doméstico. En segundo lugar, la persona empleadora no es necesariamente empresaria. Finalmente, en ocasiones las trabajadoras de hogar no se sienten trabajadoras al uso, no suelen conocer sus derechos ni cómo defenderlos, y una buena parte de ellas trabaja o ha trabajado en la economía sumergida.

De este modo, para entender las especificidades del empleo de hogar cabe destacar otros elementos fundamentales: la evidente infravaloración e invisibilidad de las trabajadoras, estrechamente ligada a la desvalorización social de las tareas domésticas que suelen recaer sobre las mujeres en el ámbito doméstico reproductivo; y la alta feminización del sector (Carrasco et al., 2011).

\subsection{El trabajo de hogar en el sistema de reproducción social}

Pero, ¿por qué estas especificidades del sector? En un marco de análisis más amplio, se constata que, históricamente, en el sistema capitalista se ha separado el trabajo productivo del reproductivo, invisibilizando al segundo y reduciéndolo a la esfera doméstica. El pensamiento económico contribuyó de manera decisiva a su desvalorización, al asociar progresivamente el trabajo al mercado y al salario.

El trabajo de hogar remunerado remite en la actualidad a dos realidades laborales. Incorpora, por una parte, las tareas de reproducción y provisión de los bienes materiales para el mantenimiento físico de las personas (como la alimentación, la higiene, la salud); y, por otro, las tareas de cuidados directos de personas en situación de dependencia (menores, tercera edad, necesidades especiales). Aunque no siempre se reconoce como tal, el trabajo de hogar resulta, en su conjunto, necesario y central para el mantenimiento de la buena vida (Pérez Orozco, 2006).

Sobre la esencialización y subvaloración de las tareas domésticas y de cuidados, el pensamiento feminista plantea que el trabajo de cuidados trasciende la frontera del espacio no monetizado. Subraya que, al evidenciarse la fragilidad de los límites entre lo público y lo privado, la economía de cuidados constituye un aspecto relevante de la reproducción social y, por lo tanto, resulta necesario re-organizar la manera en que la sociedad la enfoca.

Siguiendo a Carmen Gregorio Gil (2010: 102), no deberíamos analizar esta cuestión al margen de las relaciones históricas y económico-políticas de producción, ni de las dimensiones subjetivas e identitarias. Por ello, la autora plantea la necesidad de politizar estas tareas, sacándolas del espacio del hogar y de su asociación con lo femenino, para situarlas en el centro de procesos políticos e históricos. En efecto, las feministas destacan que lo que permanece oculto no es tanto el trabajo doméstico y de cuidados, sino la relación que mantiene con el sistema de producción capitalista. La invisibilidad del nexo entre ambas esferas produce 'rentabilidad', facilitada por el desplazamiento de costes de reproducción de la fuerza de trabajo hacia la esfera doméstica, y en concreto, hacia las mujeres.

Actualmente existe una crisis en el sector de los cuidados, que demuestra que los arreglos en este sentido son insatisfactorios, insuficientes, precarios y no libremente elegidos (Pérez Orozco, 2012). Esta situación ha puesto de manifiesto que la oferta de cuidados de las mujeres no es lo infinita que parecía ser. La escasez crónica de servicios públicos y el desarrollo insuficiente del sector privado en el Estado español han propiciado que la demanda de servicios de cuidados se haya expandido con fuerza en las últimas décadas. De ahí que un gran número de mujeres migrantes haya acudido a colmar esta grieta, reemplazando el trabajo no remunerado que, incluso hoy, recae de modo desproporcionado sobre las mujeres. Se ha venido desarrollando un nuevo modelo de cuidados, barato y flexible, basado en la inmigración (Bettio et al., 2011).

Según las cifras oficiales de septiembre de 2012 de la Seguridad Social, en el servicio de hogar familiar se contabilizaban 388.245 personas empleadas en todo el Estado español, mientras que en la CAPV el número de altas ascendía a más de 24.400. Cabe destacar que si a tales cifras incorporamos las elevadas proporciones de economía sumergida del sector, estos datos oficiales podrían triplicarse.

Para conocer las condiciones del empleo doméstico en la CAPV, resulta de interés detenernos en el estudio sobre el trabajo de hogar presentado en 2011 por el Gobierno Vasco (Departamento de Empleo y Asuntos Sociales, 2011). Como datos orientativos, podemos indicar que el $82,8 \%$ de las trabajadoras encuestadas en él se insertaron en el sector a través de personas conocidas y de manera informal. El $25,9 \%$ de las trabajadoras estaban empleadas en más de un hogar y el 80,4\% no cotizaban a la Seguridad Social, es decir, en el momento de la investigación 71.896 empleadas de hogar se encontraban trabajando en la economía sumergida. Cabe destacar que el estudio fue realizado antes de la puesta en marcha de la nueva normativa que regula el sector, por lo que algunas de estas cifras podrían ser distintas en la actualidad. 


\section{El trabajo de hogar hoy: déficits y desafíos}

\subsection{Nueva normativa}

Las condiciones particulares en que se efectúa el trabajo doméstico se combinan, por una parte, con un marco de protecciones y derechos laborales aún deficitario -en relación con otros sectores- $y$, por otra, con importantes niveles de informalidad -que históricamente han caracterizado al sector (Carrasco et al., 2011)-. Las relaciones laborales se desarrollan en el ámbito privado, sin convenios ni representación sindical. Las negociaciones y acuerdos se realizan entre cada trabajadora y la persona empleadora, basándose en unos criterios mínimos y en información que la mayoría de las veces circula por canales informales.

En el Estado español, desde 2012 se ha comenzado a implementar una nueva normativa reguladora del sector, que incorpora nuevas condiciones y algunos avances. El Real Decreto 1620/2011 forma parte de esta nueva normativa y regula el ámbito de las condiciones laborales, mientras que la Ley 27/2011 lo hace normalizando el ámbito de la Seguridad Social. Ambas comenzaron a aplicarse en enero de $2012^{2}$.
El Cuadro 1 muestra el cambio en las condiciones laborales que implica la aplicación del Real Decreto 1620/2011. Del mismo modo, el Cuadro 2 compara la Ley 27/2011, sobre incorporación al Régimen General de Seguridad Social, y el Decreto 2346 de 1969, al cual sustituye.

A pesar de la nueva normativa y del salto positivo que implica, buena parte de las condiciones generales anteriores continúan hasta la actualidad, sin mejoras reales. Persisten extensas jornadas de trabajo, descansos mínimos y poco respetados, salarios por debajo de las horas reales trabajadas, y altas en la Seguridad Social que no se cumplen.

Tanto la nueva normativa como la situación de crisis actual inciden de múltiples maneras en el modo en que se configuran las realidades concretas de las mujeres que participaron en este estudio. Así, cómo incorporar algunos de los beneficios de la nueva normativa para que la crisis afecte lo menos posible su situación particular representa un elemento que estructura el discurso de las trabajadoras de manera explícita e implícita.

\begin{tabular}{|c|c|c|}
\hline & $\begin{array}{c}\text { Ahora } \\
\text { (RD 1620/2011) }\end{array}$ & $\begin{array}{c}\text { Antes } \\
\text { (RD 1424/1985) }\end{array}$ \\
\hline Contrato & Obligatorio, por escrito. & Tanto escrito como verbal. \\
\hline Periodo de prueba & 2 meses. & 15 días. \\
\hline Nómina o recibo & \multicolumn{2}{|l|}{ Por escrito. } \\
\hline Retribución & SMI en cómputo anual (14 pagas). & Sin SMI en cómputo anual (13 pagas). \\
\hline Salario en especie & $\begin{array}{l}\text { Descuento de hasta un } 30 \% \text {. Se garantiza el SMI en } \\
\text { mano. }\end{array}$ & $\begin{array}{l}\text { Descuento de hasta un } 45 \% \text {. Sin garantizar el SMI } \\
\text { en mano. }\end{array}$ \\
\hline Tiempo de presencia & $\begin{array}{l}\text { Máximo de } 20 \text { horas por semana. Se deben retribuir } \\
\text { como horas de trabajo. }\end{array}$ & Se reconocía, pero sin máximos ni retribución. \\
\hline Descanso semanal & Derecho a 36 horas consecutivas. & $\begin{array}{l}\text { Derecho a } 24 \text { horas consecutivas y } 12 \text { horas a } \\
\text { distribuir. }\end{array}$ \\
\hline Despido & \multicolumn{2}{|c|}{ Indemnización de 20 días por año trabajado, con límite de 12 mensualidades. } \\
\hline Desestimiento & $\begin{array}{l}\text { Notificación escrita e indemnización de } 12 \text { días por } \\
\text { año, con límite de } 6 \text { mensualidades. }\end{array}$ & Indemnización de 7 días por año trabajado. \\
\hline
\end{tabular}

SMI: salario mínimo interprofesional.

Fuente: Elaboración propia a partir del Real Decreto 1620/2011 y el Real Decreto 1424/1985.

Cuadro 2. Comparativa entre la Ley 27/2011 y el Decreto 2346/1969

\begin{tabular}{|c|c|c|}
\hline & $\begin{array}{c}\text { Ahora } \\
\text { (Ley 27/2011) }\end{array}$ & $\begin{array}{c}\text { Antes } \\
\text { (Decreto 2346/1969) }\end{array}$ \\
\hline Alta en la Seguridad Social & $\begin{array}{l}\text { Derecho a cotizar desde la primera hora. El } \\
\text { empleador tiene que dar el alta. }\end{array}$ & $\begin{array}{l}\text { Derecho a cotizar con } 20 \text { horas o más, y trabajando } \\
\text { sólo en una casa. Si trabajaba en más de una, se } \\
\text { podía dar de alta ella misma como trabajadora } \\
\text { discontinua. }\end{array}$ \\
\hline Cotización & Por tramos, en función del salario. & Cuota fija, independiente del salario. \\
\hline Baja por accidente & $\begin{array}{l}\text { Se cobra el } 75 \% \text { de la base diaria de cotización, } \\
\text { desde el día siguiente. }\end{array}$ & No se reconocía. \\
\hline Baja por enfermedad & Se cobra a partir del $4^{0}$ día. & Se cobra a partir del $29^{0}$ día. \\
\hline
\end{tabular}

Fuente: Elaboración propia a partir de la Ley 27/2011 y el Decreto 2346/1969. 
Se han incorporado algunos derechos que plantean nuevas situaciones y posibilidades para este sector históricamente sumergido y precario. A partir de este escenario, las trabajadoras de hogar, gracias a un uso correcto de la información necesaria sobre sus derechos, pueden contar con más herramientas para decidir cuándo y cómo exigir y replantear sus condiciones laborales.

Sin embargo, la situación económica actual permea la realidad concreta de las trabajadoras y de las familias empleadoras. Los despidos, las rebajas de condiciones laborales, los recortes de prestaciones han repercutido en este sector. Es así cómo, a lo largo de sus diversos relatos, se ha podido ver que ambas cuestiones, crisis y normativa, se entremezclan de modo que resulta complejo disociarlas para determinar su impacto de manera aislada. Tomando esto en consideración, a continuación se apuntan algunas cuestiones vinculadas a elementos que condicionan el mundo del trabajo de hogar.

\subsection{Impactos y transiciones}

Después de más de veinticinco años sin modificaciones sustanciales en la normativa reguladora del sector del trabajo de hogar, la incidencia de los cambios introducidos a partir de enero de 2012 ha sido dispar.

Varias trabajadoras ${ }^{3}$ señalan que el proceso de transición e incorporación al nuevo régimen ha sido muy burocrático (modelos de contrato complejos, formularios difíciles de entender para ellas y para los empleadores), y que la responsabilidad ha recaído mayormente sobre ellas. Comentan que en la Seguridad Social, salvo en casos puntuales, no se les ha facilitado ni la información ni la orientación correcta sobre cómo realizar los trámites.

Por un lado, entre las trabajadoras con jornadas ordinarias nos encontramos con mujeres que, en sus testimonios, plantean que su situación laboral no ha variado considerablemente. Muchas han visto incumplidas las expectativas generadas por la nueva normativa. Las trabajadoras externas por horas que no cumplían con el mínimo de horas trabajadas (requerido por la normativa anterior) para poder cotizar y no se habían dado de alta porque valoraban que no merecía la pena económicamente (porque la cuota única les resultaba muy cara en función de sus salarios/horas trabajadas), o bien se encontraban dadas de alta bajo la figura de trabajadora discontinua, sí se han beneficiado nuevas posibilidades gracias a las modificaciones introducidas.

Por otro lado, a pesar de reconocer nuevos derechos, muchas trabajadoras se han visto perjudicadas por cambios que perciben como nada positivos o algo negativos. Un ejemplo es el descuento de su salario de más de lo que les corresponde pagar a la Seguridad Social, incluso del $50 \%$ o de la cuota íntegra.

${ }^{3}$ La mayoría de las trabajadoras de hogar entrevistadas tienen una experiencia dilatada en el sector.
Como tendencia general, se destaca la renegociación de condiciones laborales con tendencia a la baja. Hemos apreciado una reducción de carga horaria, sobre todo para las externas, lo que ha redundado en una reducción de salarios. Pero las trabajadoras enfatizan que este hecho no ha significado la disminución de tareas ni de responsabilidades.

Las pagas extraordinarias también se han convertido en una cuestión conflictiva. Con la nueva ley, se pasa de exigir el salario mínimo interprofesional (SMI) en trece mensualidades a hacerlo en catorce. Ante esto, como era de prever, muchas trabajadoras comprendieron que les correspondía cobrar pagas completas. Pero en la práctica, aunque se hubiese pactado pagas extras aparte, muchos empleadores han excusado el pago 'prorrateado' en el salario mensual percibido por las trabajadoras, cumpliendo con el SMI en cómputo anual que la ley exige. Así, algunas trabajadoras no cobran las pagas extras aparte, pero con la paradoja de que el salario mensual continúa siendo el mismo que antes, o incluso menor, porque se le ha aplicado el descuento de la cuota de la Seguridad Social.

El Gobierno que impulsó la reforma planteó que la nueva normativa serviría para sacar de la economía sumergida a las trabajadoras de hogar. Sin embargo, se ha visto que, para mantener el dinero que solían ingresar, algunas han tenido que buscar más empleo por horas, pero sin darse de alta en la Seguridad Social, al no resultarles rentable.

Entre las internas, se observan tres tendencias: mantenerse en la economía sumergida, darse de alta en la Seguridad Social en un rango salarial distinto al que les corresponde, o darse de alta en un tramo inferior al que aportaban con la anterior cuota única. En ciertos casos, la trabajadora acepta no declarar el salario real para encuadrarse en un tramo salarial menor y, de esa manera, pagar cuotas inferiores de la Seguridad Social (aunque luego se pague la diferencia 'en b'), lo que implica contar cada mes con un poco más de dinero en mano. De este modo, los contratos no reflejan las condiciones reales en que se realiza el trabajo.

Para las trabajadoras internas, persisten las jornadas laborales de 60 horas semanales y más. Con los descuentos por prestaciones en especie, continúan cobrando por debajo del SMI en función de las horas trabajadas. La jornada nocturna ha quedado sin determinar, ni en cuanto al horario ni en cuanto al precio que debe corresponderle. Y peor aún, con las deducciones por alojamiento no se reconoce el trabajo nocturno, sino que además a las trabajadoras se les descuenta dinero por pernoctar.

En sentido general, en el testimonio de las trabajadoras se percibe cierto desconocimiento ante la nueva normativa. De primera mano, les cuesta identificar su impacto, pero cuando se les pregunta por el contrato, la Seguridad Social o las bajas por enfermedad, identifican a qué nos estamos refiriendo. Por otra parte, sigue sin reconocerse el derecho al paro y las bases de cotización son las más bajas del sistema. La pres- 
tación por desempleo es uno de los elementos más reiterados en el discurso de las trabajadoras cuando se trata de valorar su lugar dentro del mundo del trabajo. Se reconocen como trabajadoras de segunda y reivindican la necesidad de igualar sus derechos a los del resto de trabajadoras/es.

\subsection{Estableciendo valoraciones}

Siguiendo los relatos de las trabajadoras de hogar consultadas, resulta difícil valorar de manera homogénea la situación actual del sector. Existen dinamismos que no permiten cerrar balances ni realizar estimaciones rígidas, pues las oscilaciones se producen incluso a lo largo del recorrido de cada trabajadora. La crisis y los cambios trastocan aún más sus realidades y sus representaciones como mujeres-trabajadoras.

Como mencionábamos antes, cuando se les preguntaba por su valoración ante la situación actual y los impactos de la nueva normativa, el elemento más destacado ha sido la falta de reconocimiento del derecho a un seguro de desempleo como uno de los grandes temas pendientes. Éste es un elemento sintomático que les recuerda que sus condiciones de trabajo -aún hoy- siguen siendo desventajosas en comparación con otros sectores laborales. Es importante destacar que lo individualizado de este trabajo, la inexistencia de convenios colectivos y la falta de agrupación o sindicalización por parte de las trabajadoras no contribuyen a la difusión de la información necesaria, ni a la orientación en torno a la defensa de sus derechos laborales.

A escala estatal, la mejora de las condiciones del sector aún no parece estar en la agenda del Gobierno, sino más bien lo contrario. Si la normativa que entró en vigor en 2012, como elemento positivo, obligaba a quienes emplean a dar de alta a las trabajadoras en la Seguridad Social, independientemente de la extensión de sus jornadas, la nueva reforma aplicada en abril de 2013 ha significado un retroceso en términos de derechos, pues ya reconoce tal obligatoriedad para empleadores cuyas trabajadoras no superen las 60 horas de trabajo mensuales.

Además, es fácil observar que la infravaloración de estos empleos y la desprotección de las condiciones laborales y de Seguridad Social de las trabajadoras se correlacionan, a su vez, con la falta de seguimiento, de inspecciones y de sanciones en caso de incumplimientos o faltas graves contra sus derechos laborales por parte de las instituciones, de la Inspección del Trabajo y de los Gobiernos. Las trabajadoras han destacado que es de vital importancia avanzar con medidas concretas, si es que realmente se quiere mejorar las condiciones del sector.

La crisis actual no ha hecho más que agravar la situación. Su impacto constituye un factor desfavorable para el posicionamiento de las trabajadoras ante la renegociación de sus condiciones laborales. El temor a perder el trabajo inmoviliza al sector, sobre todo a las trabaja- doras con familiares que dependen económicamente de ellas. Los efectos de la crisis sobre la economía familiar, además, acrecientan la rivalidad entre las propias trabajadoras. Esta rivalidad es más evidente entre trabajadoras migrantes de reciente llegada, aunque también puede percibirse entre autóctonas y migradas.

Por otra parte, la crisis de cuidados en los países enriquecidos tiene un efecto directo sobre las familias en los países empobrecidos. De este modo, teniendo en cuenta que la mayoría de las trabajadoras que colaboraron con el estudio y que realizaban labores de cuidados son migradas, es relevante destacar las rupturas familiares que se producen y la emergencia de dinámicas alternativas de reconfiguración de los lazos y roles familiares. La creación de redes y relaciones de tipo transnacional es una manera de mantener la unión familiar.

\section{Nuevos espacios de significación del trabajo de hogar}

Los nuevos espacios de significación son aquellas construcciones de significado que redimensionan la visión estereotipada del trabajo de hogar y que catalogan a las trabajadoras como precarias e invisibles. Hemos querido indagar en tres factores que consideramos relevantes como espacios de resignificación del trabajo de hogar: a) las limitaciones y aportes del trabajo de hogar; b) la red de relaciones; y c) la participación social de las trabajadoras. El primero se relaciona con la visión que las trabajadoras tienen sobre la labor que desempeñan, mientras que el segundo y el tercero se vinculan a su entorno cotidiano. Se trata, en el fondo, de apreciaciones y relaciones que, aunque pudieran parecer disociadas, se encuentran interrelacionadas. Son espacios simbólicos que las propias trabajadoras generan desde su discurso, espacios relevantes para una construcción alternativa a la visión estereotipada del trabajo de hogar y para el desarrollo de acciones de intervención en el sector.

\subsection{Aportes y limitaciones del trabajo de hogar}

Cuando se trata de valorar los aportes del trabajo de hogar, el elemento más reiterado es la independencia económica. La posibilidad de ganar esa independencia y de convertirse en el sustento de sus familias, o en parte de él, otorga un estatus importante a las mujeres como sostenedoras económicas. Esta valoración positiva se contrapone con determinadas construcciones de género que persisten dentro del sector. Un ejemplo es el caso de aquellas trabajadoras que sienten que su inserción en el mundo laboral implica un fracaso en el mundo familiar, especialmente relacionado con el cuidado de hijas e hijos. Cuando la trabajadora se siente ausente del hogar, se agudiza la sensación de abandono.

En este sentido, los prejuicios y los estereotipos de género influyen sobre la lógica distributiva de la divi- 
sión sexual del trabajo. Así como existen determinados tipos de empleo 'propios de mujeres' y 'propios de hombres', el hecho de participar del mercado laboral se vive de manera diferenciada según el sexo. Por esta razón, la carga emotiva con la que una trabajadora de hogar madre se inserta en el mundo laboral va a estar mediada por las representaciones sociales que la relacionan con las tareas de cuidado y el trabajo reproductivo en general, pero en particular dentro de su marco familiar.

Por otra parte, las trabajadoras opinan que no hay una correlación entre la responsabilidad que implican las labores que desempeñan, el trabajo que conllevan y los beneficios que se reciben a cambio. No hay una retribución social justa, sobre todo -y con esto son enfáticas- porque no hay prestación por desempleo y el suyo es un trabajo mal valorado socialmente.

Esta valoración puede verse reforzada por una percepción personal y social negativa que tiene que ver con la falta de reconocimiento, las burlas, la discriminación y el mal trato por parte de la sociedad, o de las personas empleadoras, además de por una autoestima baja, el sentimiento de deshonra y la desmotivación creciente. El discurso que desvaloriza el trabajo de hogar sostiene, en definitiva, que cualquier otro trabajo podría ser mejor. Sin embargo, no todas las trabajadoras estarían dispuestas a cambiar de empleo. La autonomía a la hora de organizar su agenda laboral y la tranquilidad con que pueden realizar sus tareas son dos elementos muy valorados y que consideran difíciles de encontrar en otros sectores del mundo del trabajo.

Es relevante destacar que, a pesar de la indefinición de las tareas y de la multiplicidad de funciones que realizan, las trabajadoras destacan su capacidad para aprender y mejorar. Las que realizan tareas de cuidados subrayan, además, la importancia de trabajar con personas dependientes, por la responsabilidad que ello conlleva. Así, cuando se es cuidadora con formación se reconoce el valor añadido por las capacidades aprendidas. También la relación afectiva que se establece con la(s) persona(s) cuidada(s) puede considerarse como un aporte del trabajo de hogar.

No obstante, la calidad de la relación que se establece con las persona(s) cuidada(s) se puede convertir en una limitación cuando el vínculo no es igual de horizontal con los empleadores. Una mala relación con éstos dificulta el desempeño laboral aun cuando los lazos afectivos con las personas cuidadas sean sólidos.

La valoración de aportes y limitaciones es una manera de resignificar el trabajo de hogar y generar un discurso que enfatiza el valor del trabajo y lo equipara al resto de sectores del ámbito laboral. El trabajo de hogar es un trabajo digno y, en palabras de las trabajadoras, "como otro cualquiera”; el trato a las trabajadoras de hogar, en consecuencia, debería ser el mismo que el dispensado a quienes trabajan en otros sectores laborales.

\subsection{Red de relaciones}

Un segundo factor de interés como espacio de resignificación lo constituye el entorno de las trabajadoras de hogar. Las trabajadoras que participaron en el estudio tienen y han tenido una extensa red de relaciones comunitarias, familiares y de amistades integrada casi en exclusiva por mujeres. La extensión y dinamismo de la red choca con la caracterización de cerrazón del trabajo doméstico.

Sin embargo, no se puede perder de vista que la red es ágil y que, en la búsqueda de empleo, en muchos casos, todo va muy rápido: te llaman, vas y al día siguiente ya estás trabajando en una casa y con una familia que acabas de conocer. Dadas las condiciones de por sí precarias del sector, la rapidez que caracteriza la red puede influir negativamente en las relaciones y condiciones laborales, por ejemplo, al no definir desde el principio las cuestiones relativas al desempeño laboral (contrato escrito, días de descanso y vacaciones).

Las redes son beneficiosas en el sentido de servir de apoyo en la búsqueda de empleo, de un lugar donde residir o de información sobre derechos, por ejemplo. Pero también se pueden desarrollar con el hermetismo de una comunidad cerrada. En este último caso, dificultan la movilidad de las trabajadoras hacia otros sectores laborales y el contacto con otras redes.

Hemos identificado dos perfiles que son más vulnerables a esta perversión de la red de relaciones: las trabajadoras de hogar migrantes de reciente llegada y las trabajadoras en régimen interno. Ambos se caracterizan por las dificultades de generar capital sociorrelacional propio. A su vez, en ambos cabe preguntarse sobre el mantenimiento y la función de las redes de relaciones. Si en un primer momento resultan indispensables para aportar la información y orientación necesaria en la búsqueda de empleo, parece que las redes se relajan, se difuminan o se desintegran una vez conseguido el trabajo.

Lo que pretendemos destacar es que las redes son diversas, se dibujan y desdibujan en dependencia de las necesidades y de la situación coyuntural de las trabajadoras. A pesar de no ser ni lineales ni persistentes en el tiempo, constituyen un importante espacio de interacción social. Pero más allá de esas redes informales, existen espacios sociales organizados y establecidos que también actúan como ámbitos de interacción para las trabajadoras. Estos espacios están estrechamente vinculados a las redes.

\subsection{La participación social de las trabajadoras de hogar}

Las trabajadoras de hogar que colaboraron con el estudio creen que la participación es importante para aumentar sus conocimientos sobre derechos, sobre la realidad que las rodea: "para estar más atentas". La participación, en el fondo, es una fuente de empo- 
deramiento para el sector. Nos referimos a la participación en un sentido amplio: como gestoras, socias o dinamizadoras, pero también como consumidoras de las distintas ofertas de las organizaciones.

La valoración que las trabajadoras realizan sobre las organizaciones es positiva, porque constituyen un espacio de solidaridad y un espacio para la formación y la superación. Aunque no se participe activamente de sus ofertas, son un ámbito de interacción social especialmente bien valorado por las trabajadoras de hogar migradas internas, cuyas redes parecen ser más reducidas.

La participación social se puede analizar como parte de la conciliación entre trabajo y vida personal. Este tipo de participación depende, en buena medida, de la amplitud de la jornada laboral. Para las trabajadoras internas, lograr este tipo de conciliación es más difícil, mientras que para las externas, habitualmente, no es problemático. No obstante, en general se percibe el interés por este tipo de conciliación, así como la importancia para su desarrollo individual.

Al indagar en la relación entre las trabajadoras de hogar y las asociaciones de mujeres, encontramos que nuestras colaboradoras conocen la labor de estos grupos cuando han participado en ellos. Sin embargo, este conocimiento suele quedar restringido a las propuestas de las asociaciones en el ámbito de la formación y de la oferta de ocio. No se trata de una implicación o un activismo sistemático, sino de participaciones puntuales relacionadas con cursos, baile o gimnasia. En muchos casos, incluso el hecho de acudir al espacio de una asociación, aunque sea de manera esporádica e informal, es un elemento positivo para la interacción social.

Cuando se trata de organizaciones distintas de las asociaciones, las referencias han sido principalmente hacia los espacios de la iglesia católica, con una mención especial a Cáritas. La relación con Cáritas se da en cuatro sentidos esenciales: a) el voluntariado de forma continuada o esporádica (por ejemplo, echando una mano en la organización de una fiesta); b) la participación en cursos, algunos de ellos exclusivamente para mujeres; c) la solicitud de ayuda social; $y$ d) las demandas relacionadas con el empleo. No obstante, la iglesia católica también ofrece otros espacios relevantes de participación social, como grupos de encuentro, en los que algunas trabajadoras de hogar han participado como gestoras y dinamizadoras.

Por otro lado, independientemente del lugar preponderante que tiene la iglesia católica como oferta religiosa en la CAPV, consideramos que también es importante mencionar la existencia de ámbitos de participación de distintas corrientes protestantes que han ido ganando espacio, sobre todo en la última década (Rodríguez Fernández y Uriarte, 2010: 99). Se trata de una oferta religiosa que se ha caracterizado, sobre todo, por acoger a la población migrante latinoamericana y africana.
Cuando nos referimos a la participación en las organizaciones de las iglesias, no existe una diferenciación relevante en cuanto a trabajadoras externas o internas. Pero sí es significativo el hecho de que las experiencias relacionadas con la solicitud de ayudas o de inscripción en la bolsa de empleo, por lo general, son referidas por mujeres migradas. También resulta interesante señalar la importancia de las redes que se tejen dentro de las instituciones religiosas, por lo significativas que son para la vida de las personas. Estamos hablando de redes que reproducen y fortalecen construcciones de sentido atravesadas por el elemento religioso, las cuales condicionan la manera en que estas mujeres se enfrentan al mundo en general, e incluso al mundo del trabajo.

Dentro del ámbito de la participación, también hemos querido indagar en la relación de las trabajadoras con los sindicatos. Sin embargo, es difícil obtener una valoración de la labor de los sindicatos y su actividad en el ámbito del trabajo de hogar, porque es una opción organizativa que no se suele contemplar en un trabajo tan individualizado como el empleo doméstico. La mayoría de las trabajadoras que han participado del estudio ni siquiera se habían planteado acercarse a un sindicato.

No obstante, en el grupo de discusión sí emergió el debate sobre la creación de un grupo que implique la participación de las trabajadoras y su compromiso, grupo que podría tomar la forma de un sindicato. Al preguntar sobre por qué no existe un sindicato del gremio, las integrantes del grupo de discusión apuntaron a una falta de voluntad inicial y al miedo a la participación. En este sentido, piensan en el perfil concreto de una persona "de aquî" que conozca el entorno y que ‘encienda la chispa' de la participación sindical.

La cuestión del miedo no es menor, pues históricamente ha sido un importante elemento de coacción para la organización de los trabajadores y trabajadoras, la manifestación de sus peticiones y para la exigencia de sus derechos. Por lo tanto, consideramos que es un elemento en el que es preciso trabajar. Un paso podría ser el establecimiento de redes de comunicación entre trabajadoras de hogar migradas y trabajadoras de hogar nacidas en el Estado español.

Finalmente, es importante mencionar que la localidad de Basauri cuenta con una Casa de las Mujeres, Marienea, pionera en su campo, que está integrada por el Área de Igualdad del Ayuntamiento y el Centro de Información de la Mujer, y en la que participan activamente distintas asociaciones. Pero a pesar de la relevancia del trabajo que se realiza en Marienea, en general hay un desconocimiento de su labor por parte de las trabajadoras de hogar.

Marienea constituye un lugar de interés para la creación de ámbitos o acciones de apoyo al colectivo de trabajadoras de hogar. De ahí que sea importante la valoración que las trabajadoras tengan de la Casa de las Mujeres, independientemente de que no conozcan en profundidad el trabajo que allí se realiza. 
Según sus opiniones, Marienea les podría ofrecer, sobre todo, espacios de ocio y para la interacción social. En cuanto a este último punto, las mujeres participantes en el estudio subrayan la necesidad de que las propias trabajadoras salgan a buscar y crear esos espacios. En el fondo, se trata de lugares donde ejercer el libre derecho a expresarse, donde ser escuchadas, donde aprender y conocer en el compartir.

\section{Nuevos rumbos}

\subsection{Hacia la mejora mínima de las condiciones laborales y la garantía plena de derechos}

Las vías para mejorar la situación de las trabajadoras de hogar, en lo personal y en lo colectivo, están en estrecha relación con las representaciones del trabajo y con las proyecciones de futuro de las entrevistadas. La mejora de sus condiciones generales se confunde automáticamente con la mejora de las condiciones laborales, descuidando otros muchos ámbitos que les afectan y sobre los que es preciso actuar. Aunque plantarse ante el futuro y formular propuestas concretas no suele ser una tarea sencilla, en el plano estrictamente laboral los cambios que se plantean son claros y se enumeran contundentemente.

Garantizar las mínimas condiciones laborales en el sector, es decir, mejorar las condiciones de trabajo y equipararlas a las de otros sectores productivos, forma parte de esas tareas inmediatas: asegurar el derecho al paro, a cotizar en la Seguridad Social, a las bajas, las vacaciones y a los días de descanso; permitir la conciliación familiar y personal; cumplir con la declaración de la renta; incrementar el salario (estableciendo mínimos salariales y un sistema de proporcionalidad si se trata de trabajo por horas); así como disponer de nóminas cumplimentadas para poder percibir también otros servicios.

Tomando en cuenta la diversidad del sector del empleo doméstico y de cuidados, hay otras propuestas específicas, dependiendo de las condiciones laborales, del régimen de trabajo o de las tareas que realizan: entre las trabajadoras externas y con pocas horas de trabajo, la proporcionalidad en el salario; entre las migrantes internas que no tienen a dónde ir fuera del ámbito de trabajo, lugares de esparcimiento y descanso. Cabe también mencionar la necesidad de normativizar la relación con las personas empleadoras. En estas reivindicaciones a "los jefes", se entrevé la identidad de las trabajadoras como colectivo.

\subsection{Hacia la revalorización del trabajo doméstico en el plano social, institucional y jurídico}

Otra cuestión que no se plantea abiertamente, pero que de forma latente transmiten las trabajadoras entrevistadas, es la falta de reconocimiento de las múltiples tareas que realizan y de lo necesario de su trabajo. Este reconocimiento no se ciñe al respeto que exigen por parte de quien las emplea en el espacio doméstico: el reconocimiento y la valorización se tiene que dar en todos los ámbitos y con todas las agencias y agentes; en lo social, en lo institucional y en lo jurídico.

Concretamente, las trabajadoras de hogar entrevistadas señalan dos acciones encaminadas a la normativizar las relaciones entre empleadores y empleadas. La primera consiste en activar mecanismos de presión sobre las personas empleadoras, especialmente en el plano jurídico, a fin de forzar el cumplimiento de las normas. Otra acción, no muy alejada de la anterior, consiste en proporcionarles mayor información sobre el trabajo doméstico y de cuidados, para generar sensibilización y concienciar.

Con respecto a las autovaloraciones de las trabajadoras y a sus valoraciones sobre el trabajo de hogar, consideramos central lograr una sensibilización de la sociedad con respecto al trabajo reproductivo. Las trabajadoras de hogar cubren las grietas de un sistema social que se apoya en las mujeres para cubrir las necesidades reproductivas. Las grietas se agrandan en un periodo en el que las necesidades de cuidado son mayores que nunca y cada vez más mujeres aspiran a un trabajo remunerado. Por ello, remarcamos la necesidad de poner sobre la mesa la existencia de esas grietas y la realidad de aquellas mujeres precarizadas e infravaloradas que, silenciosamente, se han ocupado de minimizar sus efectos sobre la sociedad.

Podemos concluir que, en general, se considera que el trabajo de hogar está infravalorado. No obstante, se aprecia un cambio en la manera en que es percibido socialmente. Al preguntarles sobre este tema, las trabajadoras se debaten entre unas y otras posiciones. El discurso es ambiguo en ocasiones, incluso una sola trabajadora puede sostener valoraciones contrapuestas, pero en general la tendencia va en el sentido de percibir esa transformación.

\subsection{Hacia la colectivización}

Tal y como hemos señalado, una de las características más importantes del trabajo de hogar es la paradoja entre la individualidad y la autonomía. Para muchas trabajadoras, es fundamental poner en marcha mecanismos de colectivización, esto es, formar un grupo, juntarse, hablar, (re)conocerse. En este sentido, teniendo en cuenta la sensación de encierro que viven algunas, la colectivización se presenta como una necesidad personal y grupal.

Los espacios de encuentro y (re)conocimiento que las propias trabajadoras demandan de forma unánime deben promover la ruptura de tabúes y la deconstrucción colectiva de prejuicios. Todo ello ayudaría a neutralizar la rivalidad que muchas detectan en el sector. Se trata de una competencia que se traduce en actitudes reservadas, de desconfianza o egoísmo por parte de unas trabajadoras hacia otras. La crisis parece 
haber agudizado estas percepciones y actitudes. Así, es necesario fomentar espacios de interacción entre las trabajadoras y prestar especial atención a los tiempos y a los ritmos de aquellas mujeres cuyas condiciones laborales dificultan la conciliación y la colectivización.

El recorrido de las trabajadoras suele ser sinuoso, pero en el camino, ellas mismas van siendo conscientes de lo importante de la colectivización. Aunque les cuesta, reconocen elementos que comparten con otras más allá de su individualidad. Pero esto, cabe recordar, implica a todos y todas (en diferentes ámbitos y con recursos variados), porque el trabajo reproductivo, imprescindible para una buena vida, es responsabilidad social y colectiva, y merece y requiere ser reorganizado.

\section{Consideraciones finales}

El trabajo de hogar es un tipo de empleo caracterizado por la feminización, la precariedad y la invisibilidad. Las condiciones de trabajo individualizadas, la atomización y soledad en el lugar de trabajo, unidas al tipo de tareas que se realiza, han provocado que la capacidad de negociación de las trabajadoras de sus condiciones de trabajo sean limitadas, como limitada es la percepción social en lo que al trabajo de hogar se refiere.

Uno de los obstáculos para la mejora de las condiciones de trabajo del sector es la propia falta de conocimiento de las trabajadoras sobre sus derechos y la difusa definición de los límites de las obligaciones que propone la legislación vigente. Si indagamos en las dinámicas que se producen, podemos apreciar que, en la práctica, el trabajo de hogar engloba toda una multiplicidad de tareas que no quedan claramente definidas de antemano, sino que se van imponiendo y adoptando según el requerimiento de las personas empleadoras.

En relación a las mejoras de las condiciones laborales que propone la nueva normativa, hay que resaltar los impactos diferenciados entre las trabajadoras que realizan cuidados y las que realizan exclusivamente labores domésticas. Se trata de valoraciones 'confusas' que han traído como consecuencia una renegociación con tendencia a la baja de las condiciones laborales. En general, la regulación es deficitaria. La diversidad y variabilidad de situaciones sociolaborales favorecen vacíos que precarizan al sector y que inciden negativamente sobre sus posibilidades de pensarse como un colectivo. Ejemplos de ello son la indefinición sobre las pagas extra, la permisibilidad respecto a los contratos que no reflejan las condiciones reales y las extensas jornadas laborales (sobre todo, para trabajadoras internas). El propio carácter deficitario de la nueva normativa dificulta que las trabajadoras salgan de la economía sumergida.

Sin embargo, es importante remarcar algunos de los elementos positivos de la nueva regulación: el cobro del SMI en cómputo anual, el reconocimiento del abono de las horas de presencia, el descanso semanal de las 36 horas continuadas, la obligación de comunicar por escrito las condiciones del contrato, el alta en la Seguridad Social desde la primera hora de trabajo y el reconocimiento de los accidentes laborales.

Como hemos podido apreciar, el trabajo de hogar no está separado de las contingencias sociales. Tiene un lugar importante, aunque poco reconocido, dentro de las dinámicas económicas mundiales y, por lo tanto, su configuración y la manera en que se nos presenta en la actualidad depende de procesos que sobrepasan los límites de los casos puntuales del sector del trabajo de hogar. Es en esta perspectiva ampliada donde nos hemos situado para comprender, conocer e interpretar la interrelación entre la nueva normativa, la crisis y los nuevos rumbos del sector en la localidad de Basauri.

De este modo, vislumbramos importantes factores que pueden ayudar a perfilar espacios de oportunidad para las trabajadoras de hogar. Se trata de elementos positivos que sería preciso destacar en cualquier acción encaminada a poner en su justo valor el lugar del trabajo de hogar en el sistema de reproducción social, sobre todo, porque son apreciaciones surgidas del propio discurso de las trabajadoras. La independencia económica es el espacio de revalorización del trabajo de hogar más relevante. Así, consideramos que este tipo de autonomía constituye un factor remarcable en el proceso de empoderamiento del sector y de su toma de conciencia como colectivo.

Por otra parte, consideramos que la construcción de redes de relaciones y la participación social son factores de empoderamiento del sector. El intercambio en estos ámbitos es relevante para las trabajadoras, independientemente de que las redes de relaciones disten mucho de ser un espacio permanente en el tiempo y carente de contradicciones. Del mismo modo, no hay un tipo de participación social, sino diversas maneras de interacción en ámbitos diferentes. Aquí lo relevante es el valor que las trabajadoras otorgan a las redes y a su participación social, y la importancia que estos espacios pueden tener en la formación de una conciencia colectiva.

Sería especialmente importante utilizar estas opciones organizativas para fomentar procesos que ayuden a la colectivización de las trabajadoras. El individualismo es un elemento distintivo que se manifiesta en el discurso de las trabajadoras como una inquietud latente, pero no por ello menos importante. Sus efectos sobre las posibilidades de generar acciones conjuntas se evidencian, sobre todo, en la falta de una visión que les permita traspasar el umbral de su experiencia personal para pasar al conjunto de experiencias como colectivo. De lo que se trata es de utilizar las ventajas de la colectivización para canalizar las necesidades de las trabajadoras, y que este proceso se convierta en una oportunidad en sí misma para su desarrollo futuro. 
Dos factores atraviesan la trayectoria laboral de las trabajadoras: la condición de clase y la cuestión de género. Ambos elementos pueden constituirse como la base sobre la cual incidir en la materialización de los nuevos rumbos que aquí han sido planteados. Constituyen, además, un marco de oportunidades para construir una identidad común y comenzar a caminar como colectivo hacia la búsqueda de vías de solución a sus problemas y de mejora de sus condiciones laborales, y a incidir en el necesario proceso de reconocimiento del trabajo reproductivo y de sensibilización social.

Finalmente, es importante destacar que Basauri es una localidad particularmente afectada por la crisis de cuidados y por la crisis socioeconómica, aunque sea toda la población vasca la que se encuentra, en

\section{Referencias bibliográficas}

(2011): “Ley 27/2011, de 1 de agosto, sobre actualización, adecuación y modernización del sistema de Seguridad Social”, Boletín Oficial del Estado, no 184 , 2-8-2011, págs. 87.495-87544 [rhttp:// www.boe.es/boe/dias/2011/08/02/pdfs/ BOE-A-2011-13242.pdf $>$, consultado el 12-122012].

(2011): "Real Decreto 1620/2011, de 14 de noviembre, por el que se regula la relación laboral de carácter especial del servicio del hogar familiar", Boletín Oficial del Estado, ํㅜ 277, 17-11-2011, págs. 119.046-119.057 [khttp://www.boe.es/boe/ dias/2011/11/17/pdfs/BOE-A-2011-17975.pdf>, consultado el 4-12-2012].

(1985): “Real Decreto 1424/1985, de 1 de agosto, por el que se regula la relación laboral de carácter especial del servicio del hogar familiar", Boletín Oficial del Estado, nำ193, 13-8-1985, págs. 25.617-25.618 [<http://www.boe.es/ diario_boe/txt.php?id=BOE-A-1985-17108>, consultado el 4-12-2012].

(1969): “Decreto 2346/1969, de 25 de septiembre, por el que se regula el Régimen Especial de la Seguridad Social del Servicio Doméstico", Boletín Oficial del Estado, n-247, 15-101969, págs. 16.109-16.115 [<http://www.boe. es/buscar/doc.php?id=BOE-A-1969-1187), consultado el 4-12-2012].

BETTIO, F. et al. (2011): "Cambios en los regímenes de cuidados y migración femenina: el 'care drain' en el Mediterráneo", en CARRASCO, C. et al. (eds.), El trabajo de cuidados. Historia, teoría y políticas, Madrid, Catarata, págs. 305-335.

CARRASCO, C. et al. (2011): "Introducción. El trabajo de cuidados: antecedentes históricos y debates actuales", en CARRASCO, C et al. (eds.), El trabajo de cuidados. Historia, teoría y políticas, Madrid, Catarata, págs. 13-95. el actual contexto de crisis, ante la oportunidad de volver a reflexionar sobre la crisis de cuidados y de valores; a dar una respuesta colectiva y efectiva ante los retos presentes; y a construir su futuro en lo que a sostenibilidad de la vida y de lo social se refiere.

En este sentido, se abren nuevas líneas de investigación-intervención con otras agencias y agentes del entorno de las trabajadoras, entre los que destacan las propias personas empleadoras y personas cuidadas. La necesidad de abrir el ámbito de estudio resulta fundamental si se quieren superar -tanto en la teoría como en la práctica- aquellas concepciones que sostienen que la vida y su cuidado cotidiano es un asunto que debe resolverse en el ámbito en lo privado y por parte de las mujeres.
DEPARTAMENTO DE EMPLEO Y ASUNTOS SOCIALES (2011): Estudio de situación laboral de las personas empleadas en servicio doméstico de la CAPV, Vitoria-Gasteiz, Eusko Jaurlaritza-Gobierno Vasco.

GREGORIO GIL, C. (2010): “Debates feministas en el análisis de la inmigración no comunitaria en el Estado español. Reflexiones desde la etnografía y la antropología social”, Relaciones Internacionales, $\mathrm{n}$ 우 14, págs. 95-115.

ORGANIZACIÓN INTERNACIONAL DEL TRABAJO (2011): Un trabajo decente para las trabajadoras y los trabajadores de hogar. Convenio 189. Recomendación 201, Ginebra, Organización Internacional del Trabajo [<http://www. ilo.org/travail/whatwedo/publications/ WCMS_168267/lang--en/index.htm>, consultado el 12-12-2012].

PÉREZ OROZCO, A. (2012): “De vidas vivibles y producción imposible" [<http://www.decrecimiento. info/2012/02/de-vidas-vivibles-y-produccion. html>, consultado el 19-3-2013].

- (2006): "Amenaza tormenta: la crisis de los cuidados y la reorganización del sistema económico", Revista de Economía Crítica, $\mathrm{n}-5$, págs. 7-37.

ROCO et al. (2013): Necesidades y oportunidades de las trabajadoras de hogar de Basauri. Una experiencia de intervención colectiva, Área de Igualdad del Ayuntamiento de Basauri; Farapi S.L. [inédito].

RODRÍGUEZ FERNÁNDEZ, L.; y URIARTE, L. (2010): “El cristianismo reformado y evangélico", en RUIZ-VIEYTEZ, E. (dir.), Pluralidades latentes. Minorías religiosas en el País Vasco, Barcelona, Icaria, págs. 96-150. 